\title{
Influence of Red Mud Proportion on Circular Concrete-Filled Steel Tubular Short Columns
}

\author{
Wu Bin (iD, ${ }^{1,2}$ Tan Zhuoying, ${ }^{1}$ Li Fan, ${ }^{3}$ and Wang Sun ${ }^{4}$ \\ ${ }^{1}$ School of Civil and Resource Engineering, University of Science and Technology Beijing, Beijing 100083, China \\ ${ }^{2}$ Department of Construction Engineering, Liaoning Provincial College of Communications, Shenyang, Liaoning 110122, China \\ ${ }^{3}$ Hannoer Greenland Venue Management Co., Ltd., Shanghai 100083, China \\ ${ }^{4}$ Architectural and Civil Engineering College, Shenyang University, Shenyang, Liaoning 110044, China \\ Correspondence should be addressed to Wu Bin; 66084537@qq.com
}

Received 30 March 2020; Revised 22 June 2020; Accepted 30 July 2020; Published 24 August 2020

Guest Editor: Norbert Randl

Copyright ( $2020 \mathrm{Wu}$ Bin et al. This is an open access article distributed under the Creative Commons Attribution License, which permits unrestricted use, distribution, and reproduction in any medium, provided the original work is properly cited.

\begin{abstract}
Tests on twelve circular concrete-filled steel tube stub columns with mixed red mud and three circular concrete-filled steel tube stub columns to investigate the influence of the mixed proportion of red mud on the mechanical behavior of axial compressive circular concrete-filled steel tube stub columns are reported. It is found that with the increase of red mud content, the ultimate load increases first and then decreases; on the contrary, the ultimate displacement decreases first and then increases; the specimen stress reaches the proportion limitation as the steel tube longitudinal strain is around $160 \mu \varepsilon$ and reaches the yield limitation as the steel tubes' longitudinal strain is around $4400 \sim 5000 \mu \varepsilon$. The axial compressive bearing capacity empirical formulation of concretefilled steel tubes stub columns mixed with red mud is proposed. The theoretical calculation results agree well with those experimental data.
\end{abstract}

\section{Introduction}

Circular concrete-filled steel tube (CCFST) can provide excellent structural properties, such as high bearing capacity and high ductility, and the steel tube of CCFST can be used as permanent formwork to reduce the construction schedule without any effect by seasonal climate. Therefore a considerable amount of studies on CCFST have been carried out in recent decades [1-9], which make this kind of structure more and more widely used in subways, tunnels, bridges, high-rise, and super high-rise buildings.

Various studies of the utilization of solid waste in the construction industry have been conducted in recent years [10-13]. Most of the solid wastes generally produce certain radiation and corrosiveness, and the poured concrete with mixing those solid wastes normally engenders attribute of high dispersion. However, the steel tube has the characteristics of radiation protection and corrosion resistance, and it has a behavior to constrain the dispersion of concrete. Therefore, the solid wastes utilized in the CCFST would greatly improve the utilization rate of solid wastes in the world. Nowadays, the research works of solid wastes in CCFST [14-16] have already been conducted and achieved some research results.

As a result, this paper takes red mud as a research object to study its effective utilization. Red mud, as a solid waste produced in the process of bauxite extraction, occupies a large amount of land. Its high alkali content causes serious pollution in the surroundings, which makes the red mud disposal and utilization increasingly prominent [17]. At present, the main field of red mud treatment is in the construction industry, and some achievements have been made. It was found that red mud had good cementations' activity and could be well utilized [18]. Liu and Poon [19] used bauxite residue-red mud instead of part of fly ash to make self-compacting concrete in order to test its mechanical behavior. It was found that the compressive strength, the splitting tensile strength, and the elastic modulus of the specimens were increased, respectively. $\mathrm{Wu}$ et al. [20] put forward the concept of the CCFST mixed with 
red mud first and conducted experimental research on pushing core concrete out of steel tube. The research result indicated that the bond slip behavior of the CCFST mixed with red mud was improved; it was proved that the cement of core concrete could be partly replaced by the red mud.

In order to investigate the influence of mixing proportion of the red mud on the mechanical behaviors of CCFST stub columns under axial compressive load, the tests on a total of fifteen specimens under axial compressive bearing load including twelve specimens of CCFST stub columns mixing with the red mud and three specimens of CCFST stub columns are reported in this paper. The main objective of these tests was twofold: firstly, to derive the empirical formulation of axial compressive bearing capacity by the discussion on the influence of mixing proportion of the red mud in CCFST stub columns; and secondly, to verify the correctness of the formulation by comparing and analyzing the calculation results and the test data.

\section{Experimental Study}

\subsection{Specimen Material}

(1) Steel tube: a seamless circular steel tube was applied. According to Chinese Code GB/T228-2002, the tensile test method of metal material at the status of room temperature, the yield strength $f_{y}$, tensile strength $f_{u}$, elastic modulus $E_{s}$, yield strain $\varepsilon_{s y}$, and Poisson's ratio $v_{s}$ will be determined, shown in Table 1.

(2) Concrete: Yatai brand 42.5R normal cement mixed with 5 15 $\mathrm{mm}$ aggregates, the river sand, and the tap water; the superplasticize was applied from Liaoning Jianfeng Industrial Co., Ltd; Bauxite residue-red mud generated in Beihai Alumina Plant, Weiqiao, Shandong Province. The chemical composition of the red mud is shown in Table 2 . The quality substitution rate of the red mud in the concrete was applied for $0 \%, 5 \%, 10 \%, 15 \%$, and $20 \%$, respectively. The mixture ratio of the red mud concrete was in accordance with the Chinese standard JGJ55-2001 mix design of normal concrete, as can be seen in Table 3.

2.2. Specimen Labels and Parameters. A total of fifteen specimens were constructed including twelve CCFST stub columns mixed with the red mud and three CCFST stub columns. A summary of the specimen information is given in Table 4. The specimens labeled as CSC are for Circular Stub Column; the fourth letter labeled as A, B, or C is for the external diameter of the specimens of $108 \mathrm{~mm}, 133 \mathrm{~mm}$, or $159 \mathrm{~mm}$, and the last Arabic numeral labeled 1, 2, 3, 4, or 5 is for the quality substitution rate of the red mud of $0 \%, 5 \%$, $10 \%, 15 \%$, or $20 \%$. $L$ is the length of the stub column; $D$ is the external diameter of the circular steel tube; $t_{\mathrm{s}}$ stands for the wall thickness of the steel tube; $r \%$ means the quality substitution rate of the red mud; $f_{c u}$ means the cubic compressive strength of concrete; $\alpha$ means the steel content; $\xi_{s}$
TABLE 1: Mechanic properties of the steel tube.

\begin{tabular}{lcccccc}
\hline Label & $\begin{array}{c}D \times t \\
(\mathrm{~mm})\end{array}$ & $\begin{array}{c}f_{y} \\
(\mathrm{MPa})\end{array}$ & $\begin{array}{c}f_{u} \\
(\mathrm{MPa})\end{array}$ & $\begin{array}{c}E_{s} \\
(\mathrm{GPa})\end{array}$ & $\begin{array}{c}\varepsilon_{s y} \\
(\mu \varepsilon)\end{array}$ & $v_{s}$ \\
\hline CSCA & $108 \times 4.5$ & 323.3 & 490.0 & 205 & 1650 & 0.27 \\
CSCB & $133 \times 4.5$ & 298.9 & 462.7 & 203 & 1600 & 0.27 \\
CSCC & $159 \times 4.5$ & 292.3 & 463.6 & 203 & 1550 & 0.27 \\
\hline
\end{tabular}

stands for the confining factor; $N_{u}^{e}$ is the ultimate bearing capacity of stub column.

2.3. Specimens Fabrication. A circular steel tube was cut into fifteen steel tubes according to the length shown in Table 4 on the automatic cutting machine. All the specimens were three times the diameter in length to reduce the end effects and to ensure that the specimens would be stub columns with minimum effect from slenderness. Each tube was welded to a $200 \mathrm{~mm} \times 200 \mathrm{~mm} \times 10 \mathrm{~mm}$ steel base plate at the bottom of the steel tube. Fifteen same size steel plates were milled with a $3 \mathrm{~mm}$ deep concentric round groove which diameter was $0.2 \mathrm{~mm}$ bigger than the external diameter of the steel tubes and was used as the movable cover plates on the top of the steel tubes. The red mud concrete was poured from the top of the steel tube and compacted with vibration until the red mud concrete was higher than the top surface of the steel tube. All the specimens were cured for 2 weeks, then the top surface of the red mud concrete-filled steel tube was ground smooth and flushed with the steel tube by using an angle polishing machine. The steel cover plate covered on the top surface of the steel tube. This was done to ensure that the load was applied evenly across the cross-section and simultaneously to the steel tube and concrete core. See Figures 1 and 2 for the fabricated test specimens.

2.4. Test Arrangement and Measurement. The loading device and measuring equipment are shown in Figures 3 and 4. All the specimens were tested with a universal testing machine with a $2000 \mathrm{kN}$ capacity in the structural engineering laboratory of Liaoning Construction Sciences Academy. The longitudinal displacement of each specimen was measured by two transducers with a measurement range of $50 \mathrm{~mm}$. The arrangement of strain gauges is shown in Figure 5. There were 8 strain gauges in total, including 4 longitudinal strain gauges and 4 circumferential strain gauges (points 1-4). The type of strain gauge was BX120-5AA, and the size was $50 \times 3$. TDS602 was used for collecting relative strain and displacement.

2.5. Loading System. According to Chinese Code GB/T 50152-2012 Standard for test method of concrete structures, the test adopted method of load increment, as shown in Figure 6. The estimated ultimate loads of the 3 series A, B, C specimens were about $900 \mathrm{kN}, 1300 \mathrm{kN}$, and $1700 \mathrm{kN}$, respectively. The preloading value was applied $10 \%$ of the estimated ultimate load in order to make a concentric adjustment imposing on specimens. Then, the loads were applied in increments of $1 / 10$ of the estimated ultimate load 
TABLe 2: Red mud chemical composition.

\begin{tabular}{|c|c|c|c|c|c|c|c|c|c|c|c|c|}
\hline & $\mathrm{Al}_{2} \mathrm{O}_{3}$ & $\mathrm{Na}_{2} \mathrm{O}_{\mathrm{k}}$ & $\mathrm{Fe}_{2} \mathrm{O}_{3}$ & $\mathrm{SiO}_{2}$ & $\mathrm{TiO}_{2}$ & $\mathrm{CaO}$ & $\mathrm{CO}_{2}$ & $\mathrm{H}_{2} \mathrm{O}$ & $\mathrm{H}_{2} \mathrm{O}$ & Loss & $\mathrm{PH}$ & Density $\left(\mathrm{g} . \mathrm{cm}^{-3}\right)$ \\
\hline$\%$ & 23.73 & 7.39 & 28.79 & 24.63 & 2.22 & 2.69 & 0.97 & 8.59 & 1 & 14.94 & 11.3 & 3.2 \\
\hline
\end{tabular}

TABLE 3: The proportion of red mud concrete $\mathrm{Kg} / \mathrm{m}^{3}$.

\begin{tabular}{lccccccc}
\hline SN & Red mud & Cement & Sand & Aggregate I & Aggregate II & Water & Superplasticize \\
\hline RMC-0 & 0 & 360 & 780 & 216 & 862 & 862 & 162 \\
RMC-5 & 18 & 342 & 780 & 216 & 862 & 162 & 162 \\
RMC-10 & 36 & 324 & 780 & 216 & 862 & 162 & 4.9 \\
RMC-15 & 54 & 306 & 780 & 216 & 862 & 162 & 4.5 \\
RMC-20 & 72 & 288 & 780 & 216 & 4.8 \\
\hline
\end{tabular}

Note: RMC labeled for red mud concrete; $0,5,10,15$, and 20 are for quality substitution rate of red mud $0 \%, 5 \%, 10 \%, 15 \%$, and $20 \%$, respectively.

TABle 4: Parameters of the specimens.

\begin{tabular}{lccccccccccc}
\hline SN & Specimen & $L(\mathrm{~mm})$ & $D(\mathrm{~mm})$ & $\mathrm{ts}(\mathrm{mm})$ & $r(\%)$ & $f_{\mathrm{y}}(\mathrm{MPa})$ & $f_{\text {cu }}(\mathrm{MPa})$ & $\mathrm{D}(\mathrm{ts})$ & $\alpha$ & $\xi \mathrm{s}$ & $N_{u}^{e}(\mathrm{kN})$ \\
\hline 1 & CSCA-1 & 324 & 108 & 4.5 & 0 & 323.3 & 36.9 & 24 & 0.19 & 2.488 & 885.6 \\
2 & CSCA-2 & 324 & 108 & 4.5 & 5 & 323.3 & 50.5 & 24 & 0.19 & 1.815 & 1003.4 \\
3 & CSCA-3 & 324 & 108 & 4.5 & 10 & 323.3 & 46.6 & 24 & 0.19 & 1.968 & 971.8 \\
4 & CSCA-4 & 324 & 108 & 4.5 & 15 & 323.3 & 44.0 & 24 & 0.19 & 2.083 & 948.6 \\
5 & CSCA-5 & 324 & 108 & 4.5 & 20 & 323.3 & 34.0 & 24 & 0.19 & 2.700 & 860.5 \\
6 & CSCB-1 & 400 & 133 & 4.5 & 0 & 298.9 & 36.9 & 29.6 & 0.15 & 1.821 & 1289.6 \\
7 & CSCB-2 & 400 & 133 & 4.5 & 5 & 298.9 & 50.5 & 29.6 & 0.15 & 1.328 & 1403.6 \\
8 & CSCB-3 & 400 & 133 & 4.5 & 10 & 298.9 & 46.6 & 29.6 & 0.15 & 1.440 & 1369.4 \\
9 & CSCB-4 & 400 & 133 & 4.5 & 15 & 298.9 & 44.0 & 29.6 & 0.15 & 1.524 & 1349.2 \\
10 & CSCB-5 & 400 & 133 & 4.5 & 20 & 298.9 & 34.0 & 29.6 & 0.15 & 1.976 & 1265.6 \\
11 & CSCC-1 & 477 & 159 & 4.5 & 0 & 292.3 & 36.9 & 35.3 & 0.124 & 1.463 & 1630.1 \\
12 & CSCC-2 & 477 & 159 & 4.5 & 5 & 292.3 & 50.5 & 35.3 & 0.124 & 1.067 & 1884.5 \\
13 & CSCC-3 & 477 & 159 & 4.5 & 10 & 292.3 & 46.6 & 35.3 & 0.124 & 1.157 & 1812.5 \\
14 & CSCC-4 & 477 & 159 & 4.5 & 15 & 292.3 & 44.0 & 35.3 & 0.124 & 1.225 & 1766.5 \\
15 & CSCC-5 & 477 & 159 & 4.5 & 20 & 292.3 & 34.0 & 35.3 & 0.124 & 1.587 & 1600.0 \\
\hline
\end{tabular}

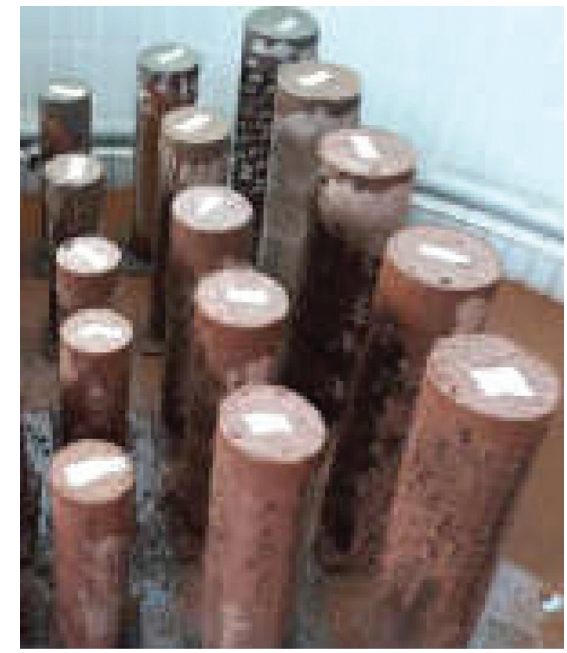

FIGURE 1: Specimens.

in the elastic range. When the target loads were reached, each target load was maintained for 2 mins on the specimen. As the load reached $60 \%$ of the estimated ultimate load $(540 \mathrm{kN}, 780 \mathrm{kN}$, and $1020 \mathrm{kN}$, respectively), the loads were applied in an increment of $1 / 20$ of the estimated ultimate load. When the target loads were reached, each target load was maintained for 2 mins as well. As the specimen was under destruction, the load continued to increase slowly. After reaching the ultimate load value, the loads were applied continuously until the deformation of the specimen was too big, then the test stopped. Each test took approximately one hour to complete. In the whole process of the test, the load readings and deformation measurements were recorded automatically by the pressure servo machine, which provided enough data points to complete the drawing of load displacement curve.

\section{Experimental Results and Discussion}

3.1. Analysis of Experimental Phenomena. At the beginning, the specimens were loaded in the elastic stage without obvious change. When the load reached $60 \% \sim 70 \%$ of the ultimate load, the shear slip line appeared on the steel tube wall. As the load reached $80 \% \sim 90 \%$ of the ultimate load, the rust on the steel tube wall started falling down, the local buckling of the steel tube happened, and the cross shear slip line emerged. Then, the specimens were in the failure stage. Because the confining factor was relatively big, the 

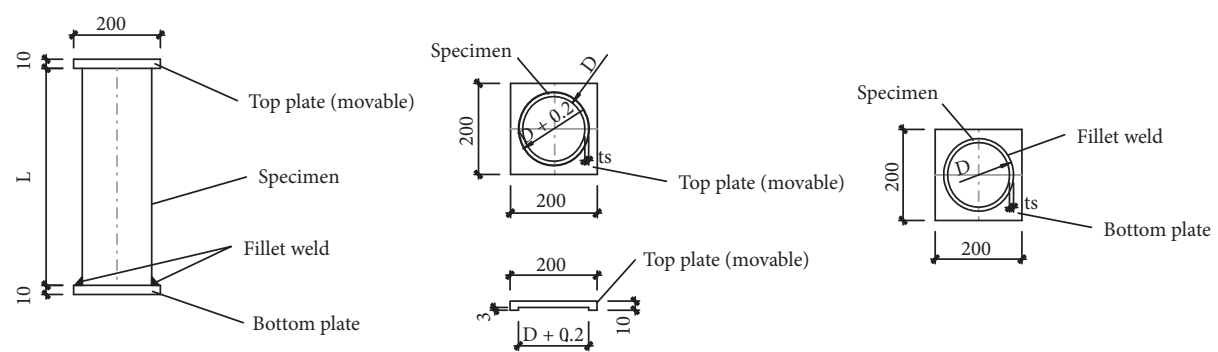

FIgURE 2: The specimens geometry.

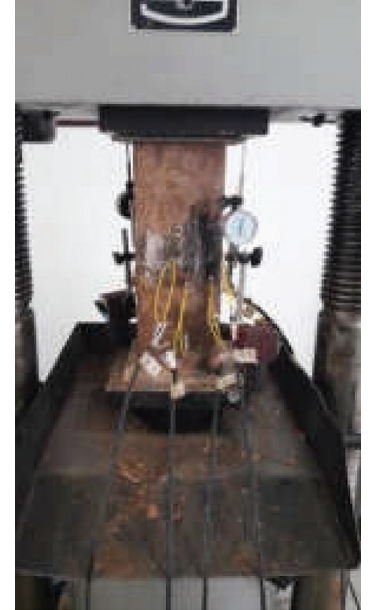

Figure 3: The loading device.

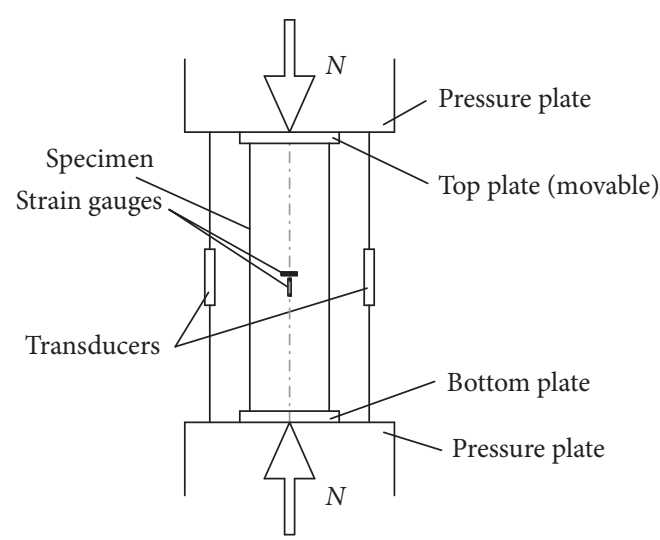

FIgURE 4: Column test layout.

drum-shaped failure occurred (Figure 7), while the specimens showed good ductility. After the ultimate load was reached, the bearing capacity of the specimens was different according to the different confining factor. For the specimens with big confining factor, the bearing capacity was slightly increased. For the specimens with small confining factor, the bearing capacity was slightly decreased. For the specimen with a moderate confining factor, the bearing capacity kept the same. The deformation of the specimens in those 3 situations was continuously increasing until the specimens were loaded to failure. The failure modality of the

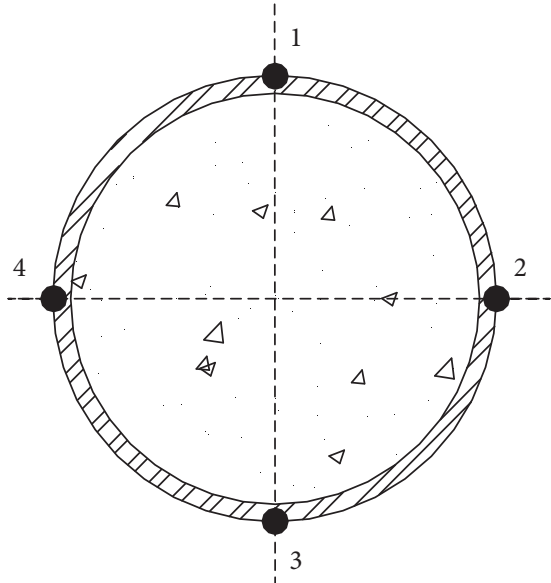

FIgURE 5: Arrangement of the strain gauges measuring equipment.

CCFST with the red mud specimen was similar to the failure modality of the CCFST specimen. Figure 8 shows all the specimens with failure mode.

3.2. Influence of Mixed Red Mud. The load $(\mathrm{kN})$ versus displacement $(\mathrm{mm})$ curves for the 3 groups specimens (A, B, C) are presented in Figure 9.

As shown in Figure 9, the load $(\mathrm{kN})$ versus axial displacement $(\mathrm{mm})$ curves for the 3 series of specimens are little different. It was found that with the increase of the quality substitution rate of the red mud $(r)$ in the CCFST stub column, the ultimate load of specimens increased first and then decreased. The ultimate load was the maximum, as $r=5 \%$, the ultimate load on the CCFST with the red mud specimens for groups A, B, and C were $1003.4 \mathrm{kN}$, $1403.6 \mathrm{kN}$, and $1884.5 \mathrm{kN}$, respectively, which increased $13.30 \%, 8.84 \%$, and $15.61 \%$ compared with those 3 CCFST specimens. As $r=20 \%$, the ultimate load on the CCFST with the red mud specimens for groups $\mathrm{A}, \mathrm{B}$, and $\mathrm{C}$ were $860.5 \mathrm{kN}, 1265.6 \mathrm{kN}$, and $1600 \mathrm{kN}$, respectively, which decreased $2.83 \%, 1.86 \%$, and $1.85 \%$ than the ultimate load on the 3 CCFST specimens. It illustrates that when the quality substitution rate of the red mud is between $0 \% \sim 20 \%$, the ultimate load on the CCFST with the red mud increases, the reasons of which are twofold: firstly, the red mud has the characteristics of pozzolanic. During the hydration of concrete, $\mathrm{Ca}(\mathrm{OH})_{2}$ was produced. It reacted with active $\mathrm{SiO}_{2}, \mathrm{Fe}_{2} \mathrm{O}_{3}$, and $\mathrm{Al}_{2} \mathrm{O}_{3}$ produced from the red mud in the second time hydration and generated the hydrate calcium 


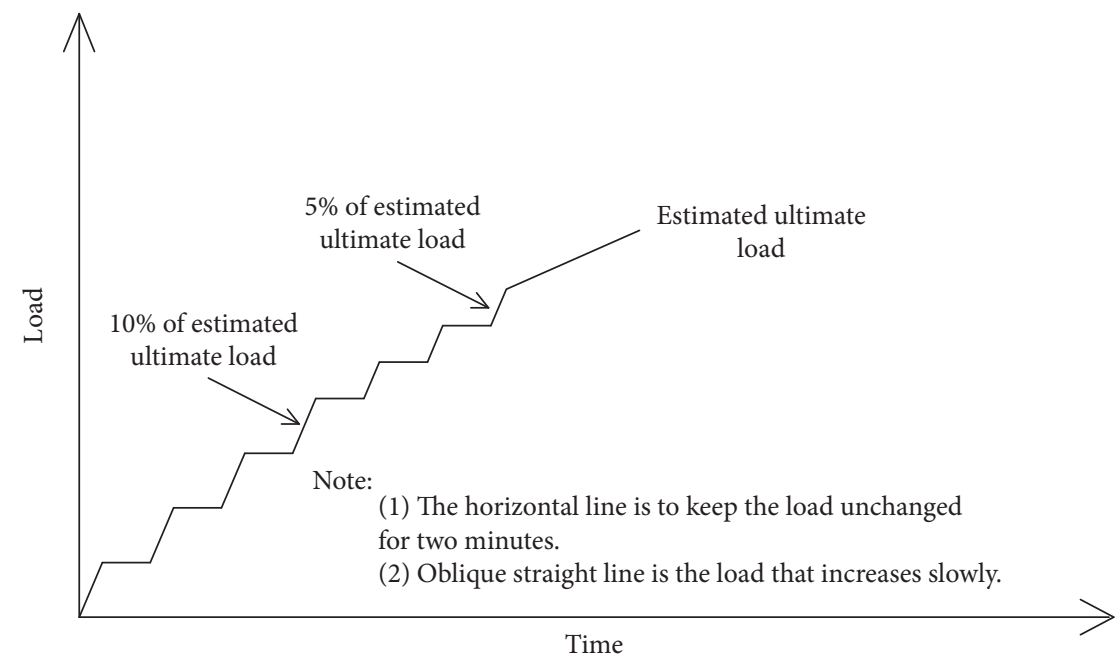

FIGURE 6: Simplified diagram of the method of load increment.
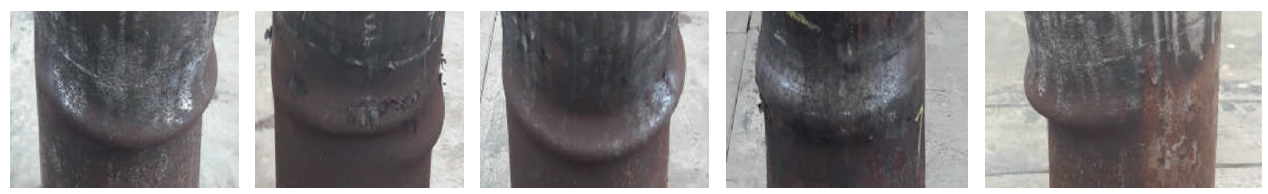

Figure 7: Local buckling of the steel tube.

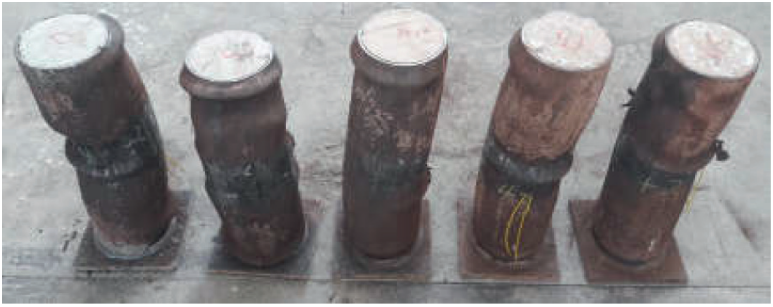

(a)

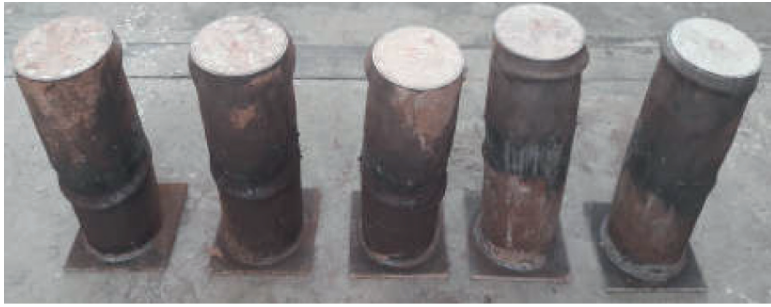

(b)

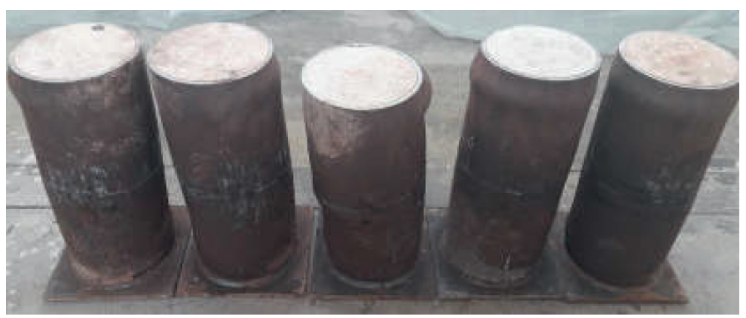

(c)

Figure 8: Failure mode of specimens. (a) CSCA. (b) CSCB. (c) CSCC.

silicate and the hydrate calcium acuminate. In the process of the reaction, $\mathrm{Ca}(\mathrm{OH})_{2}$ generated was being consumed, which caused further hydration reaction promoted. The structure of the interface between the internal medium of concrete was improved. The compressive strength of concrete was enhanced; and secondly, the red mud particles were finer after processing, its specific surface area was bigger than $400 \mathrm{~m}^{2} / \mathrm{kg}$, while the specific surface area of
Portland cement was only bigger than $300 \mathrm{~m}^{2} / \mathrm{kg}$. Therefore, the red mud played a physical filling role in the concrete. The concrete mixing with the red mud would have smaller pores and lower porosity, which caused the compactness of the concrete was raised. As a result, the compressive strength of the concrete would be improved.

As seen in Figure 9, with the increase of the quality substitution rate of the red mud $(r)$ in the CCFST stub 

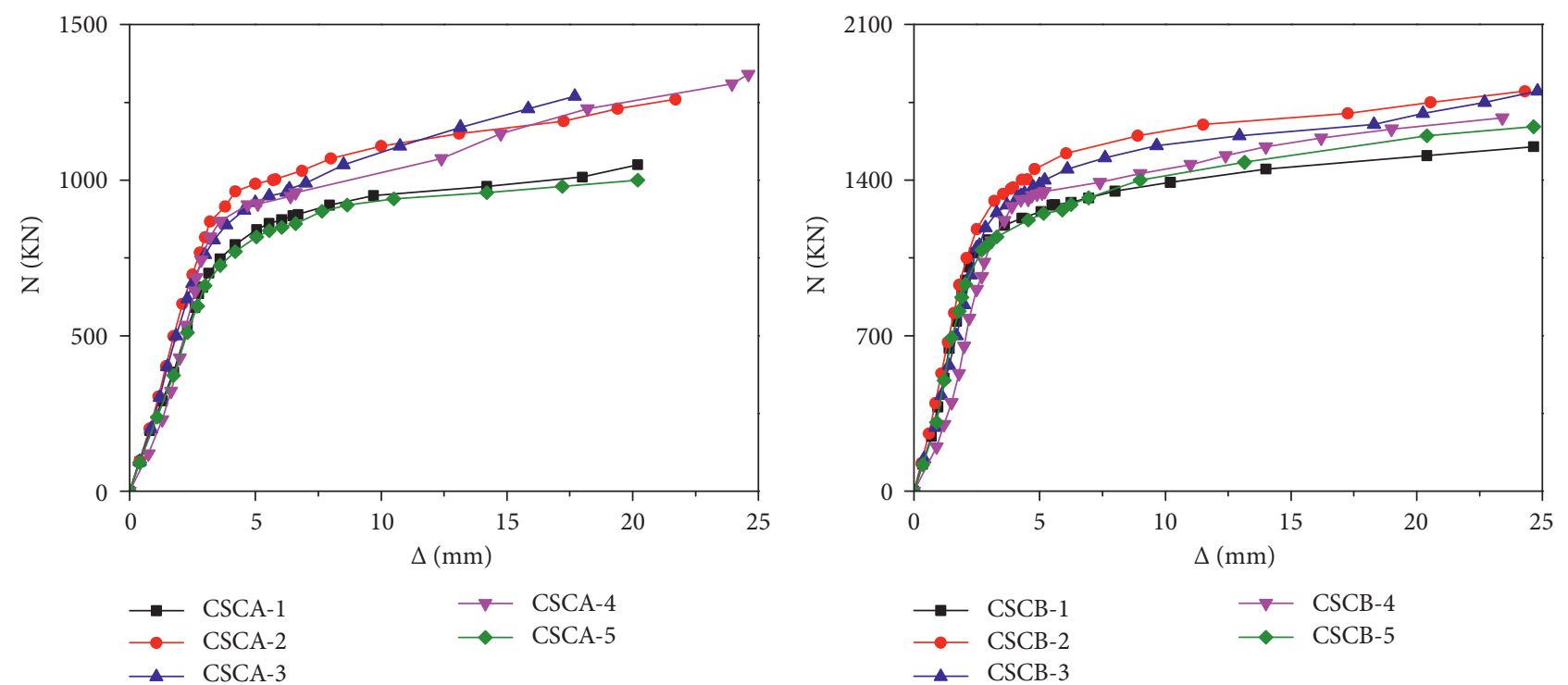

(a)

(b)

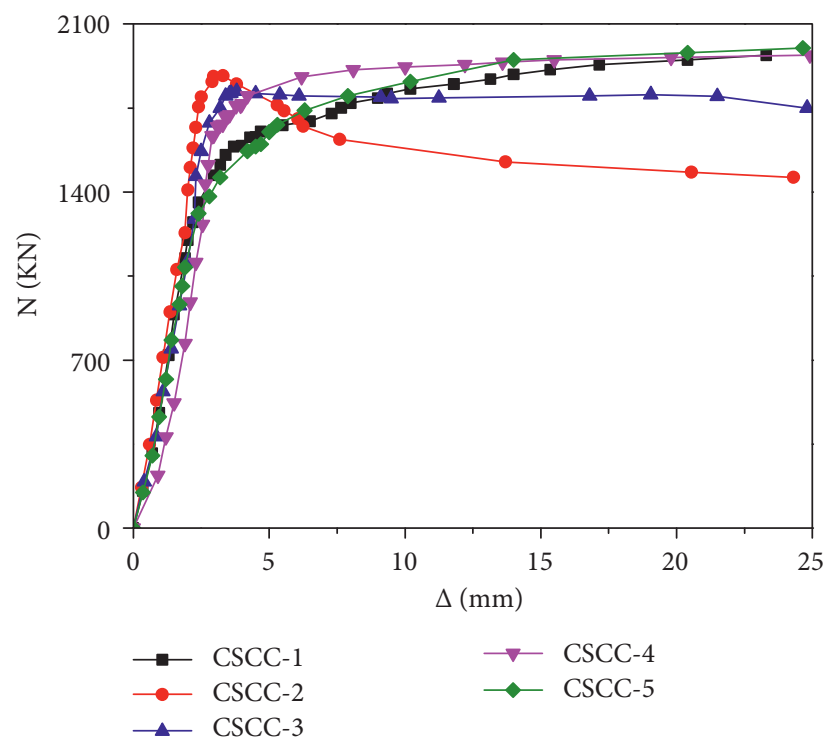

(c)

Figure 9: The load versus displacement curves. (a) Group A. (b) Group B. (c) Group C.

column, the ultimate displacement of the specimens decreased first and then increased, the ultimate displacement was minimum, as $r=5 \%$, the ultimate displacement of the CCFST with the red mud specimens for groups $\mathrm{A}, \mathrm{B}$, and $\mathrm{C}$ were $5.8 \mathrm{~mm}, 4.5 \mathrm{~mm}$, and $3.3 \mathrm{~mm}$, respectively, decreased $10.77 \%, 19.64 \%$, and $26.67 \%$ than those 3 CCFST specimens. As $r=20 \%$, the ultimate displacement of the CCFST with the red mud specimens for groups $\mathrm{A}, \mathrm{B}$, and $\mathrm{C}$ was $6.6 \mathrm{~mm}$, $5.9 \mathrm{~mm}$, and $4.7 \mathrm{~mm}$, respectively, increased 1.54\%, 5.36\%, and $4.44 \%$ than the ultimate displacement of the 3 CCFST specimens. Obviously, when the quality substitution rate of the red mud was between $0 \% \sim 20 \%$, the ultimate displacement of the CCFST with the red mud specimens decreased and the ductility became weaker compared with the CCFST specimens, the main reason of which was that the strength of the CCFST mixing the red mud was improved and the stiffness was enhanced.

3.3. Analysis of the Whole Process of Stress Strain. The nominal compressive stress of the specimen is $\sigma_{s c}=N / A_{s c}$ : $\sigma_{s c}$ is the nominal compressive stress of the specimen $N$ is the axial pressure,

$A_{s c}$ is the cross-sectional area of the specimen

The axial compressive strain of the specimen is $\varepsilon_{s l}=\Delta / L$ :

$\varepsilon_{s l}$ is the compressive strain of the specimen

$\Delta$ is the axial deformation

$L$ is the height of the specimen 


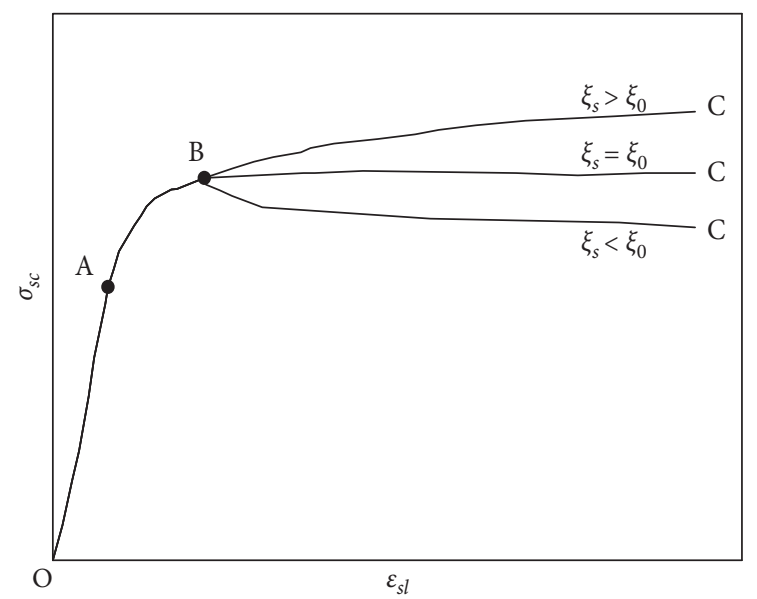

Figure 10: The $\sigma_{s c}-\varepsilon_{s l}$ relations of the specimens.

According to Figure 8, the typical $\sigma_{s c}-\varepsilon_{s l}$ curves of the specimens were obtained, as shown in Figure 10.

As can be seen from Figure 10, the curve mainly undergoes three stages: elastic stage (OA), elastic-plastic stage $(\mathrm{AB})$, and ascending/descending/horizontal stage (BC).

OA stage: the curve is linear. It indicates that the quality substitution rate of the red mud has little effect on the stiffness when the specimen is in the elastic stage. The steel tube and the red mud concrete have not been working well together. When reaching point $A$, the steel tube is in a compressive yield state, the longitudinal strain is about $1600 \mu \varepsilon$, the circumferential strain is around $450 \mu \varepsilon$, and the specimen reaches the proportional limitation.

AB stage: the specimen is in the elastic-plastic stage, and the steel tube and the red mud concrete bear the load simultaneously. With the development of the red mud concrete cracks in the steel tube, the transverse deformation exceeds the Poisson's ratio of the steel tube. Mutual extrusion produced between these two materials causes the steel tube to produce the confinement effect on the red mud concrete core. At the same time, the red mud concrete core is in a three-dimensional compressive state. Therefore, the bearing capacity of the specimen is enhanced. As reaching point $\mathrm{B}$, the longitudinal strain of the steel tube is about $4400 \sim 5000 \mu \varepsilon$, and the specimen reaches the yield limitation.

$\mathrm{BC}$ stage: when it exceeds point $\mathrm{B}$, the curve is divided into three situations according to the different confining factor. As $\xi_{s}=\xi_{0}$, the curve is basically horizontal; as $\xi_{s}>\xi_{0}$, it becomes a slowly rising curve, the bigger the confining factor is, the larger the rise range is, and vice versa; as $\xi_{s}<\xi_{0}$, it is a gradually falling curve, the smaller the confining factor is, the larger the decline range is, and vice versa. According to Table 4 and Figure 9, $\xi_{0}=1.1$.

\section{Simplified Calculation of Axial Compressive Bearing Capacity}

4.1. The Proposed Empirical Formulation of Axial Compressive Bearing Capacity of Stub Column. According to Figure 9, when the specimens reach the peak load, the deformation is

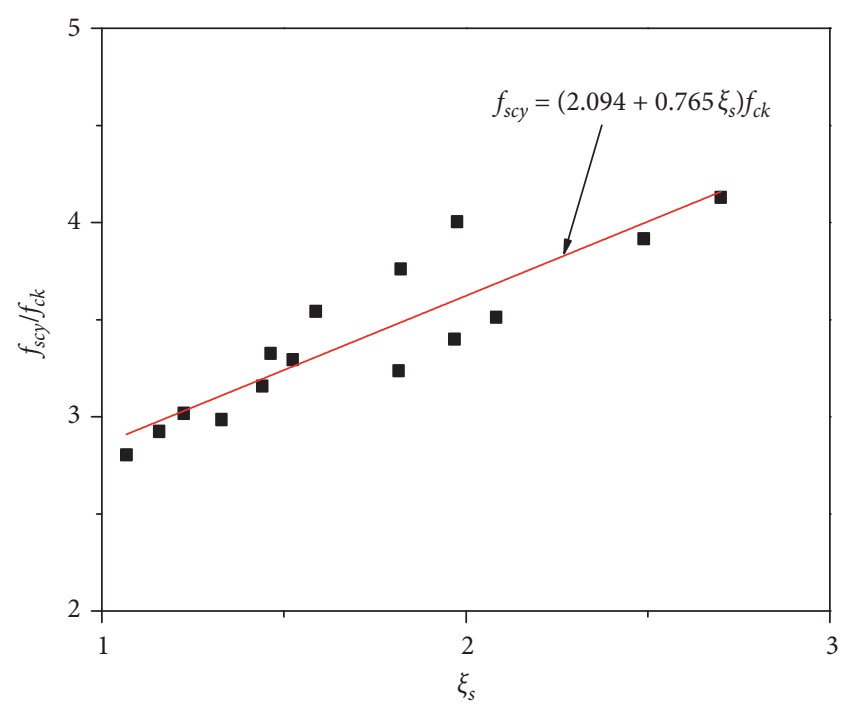

FIGURE 11: The relationship between ultimate yield strength and confining factor.

too big. The components would have lost their usage function if they were applied in the real projects. Therefore, the ultimate yield strength $f_{s c y}$ of the specimen (longitudinal strain is about $4400-5000 \mu \varepsilon$ ) determined by the stressstrain relations shown in Figure 10 is defined as the ultimate strength of the axial compressive bearing capacity of the specimen. In the range of quality substitution rate of the red mud $r=0 \% \sim 20 \%$, regression analysis of test data is carried out, as shown in Figures 11 and 12.

The formulation of $f_{s c y}$ proposed by regression analysis is as follows:

$$
f_{s c y}=\varphi_{r}\left(2.094+0.765 \xi_{s}\right) f_{c k} .
$$

Then, the axial compressive bearing capacity formulation of the CCFST stub column with the red mud is proposed as follows:

$$
\begin{aligned}
N_{u} & =f_{s c y} A_{s c}, \\
\varphi_{r} & =0.993-1.480 r+8.261 r^{2}, \\
A_{s c} & =A_{s}+A_{c} .
\end{aligned}
$$

$f_{\text {scy }}$ is the ultimate strength of axial compressive bearing capacity; $f_{c k}$ is the standard value of compressive strength of concrete; $f_{c k}=0.67 f_{c u} . \xi_{s}$ is the confining factor of steel tube; $\xi_{s}=\left(f_{y} A_{s} / f_{c k} A_{c}\right) \cdot N_{u}$ is the axial compressive bearing capacity of stub column; $A_{s c}$ is the composite section area of CCFST stub column with red mud; $A_{s}$ is the section area of steel tube of CCFST stub column with red mud; $A_{c}$ is the section area of concrete of CCFST stub column with red mud; $\varphi_{r}$ is the influence coefficient of quality substitution rate of the red mud; $r$ is the quality substitution rate of the red mud

When $r=0 \%$, it can be seen as the formulation of the axial compressive bearing capacity of the CCFST stub column. 


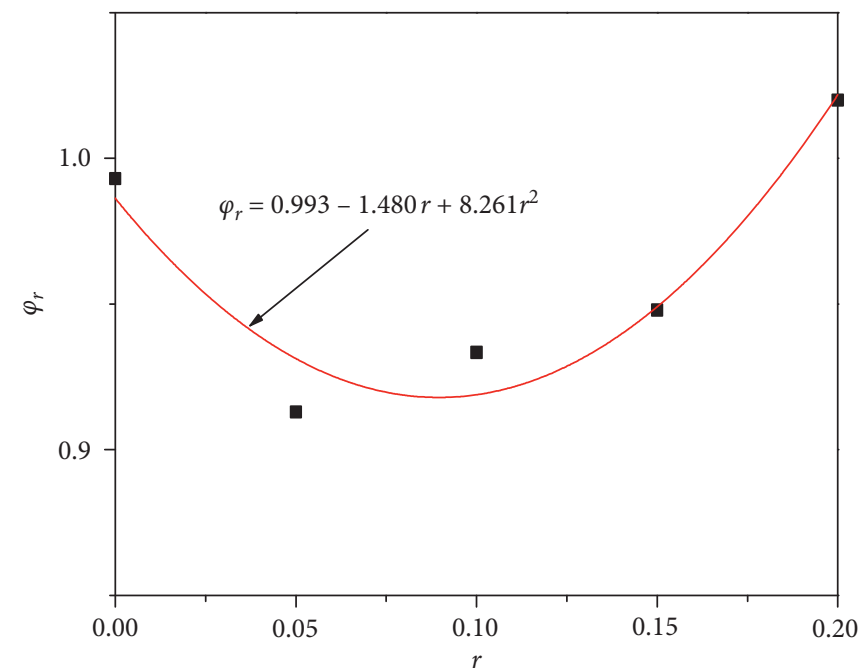

Figure 12: The relationship between ultimate yield strength and quality substitution rate of the red mud.

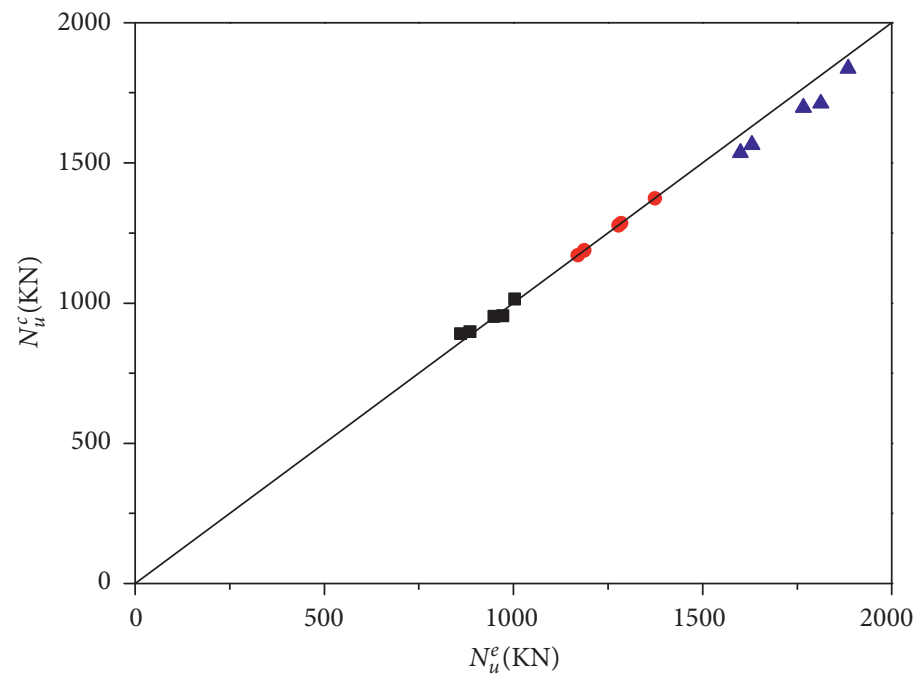

- CSCA

- CSCB

$\triangle \mathrm{CSCC}$

(a)

Figure 13: Continued. 


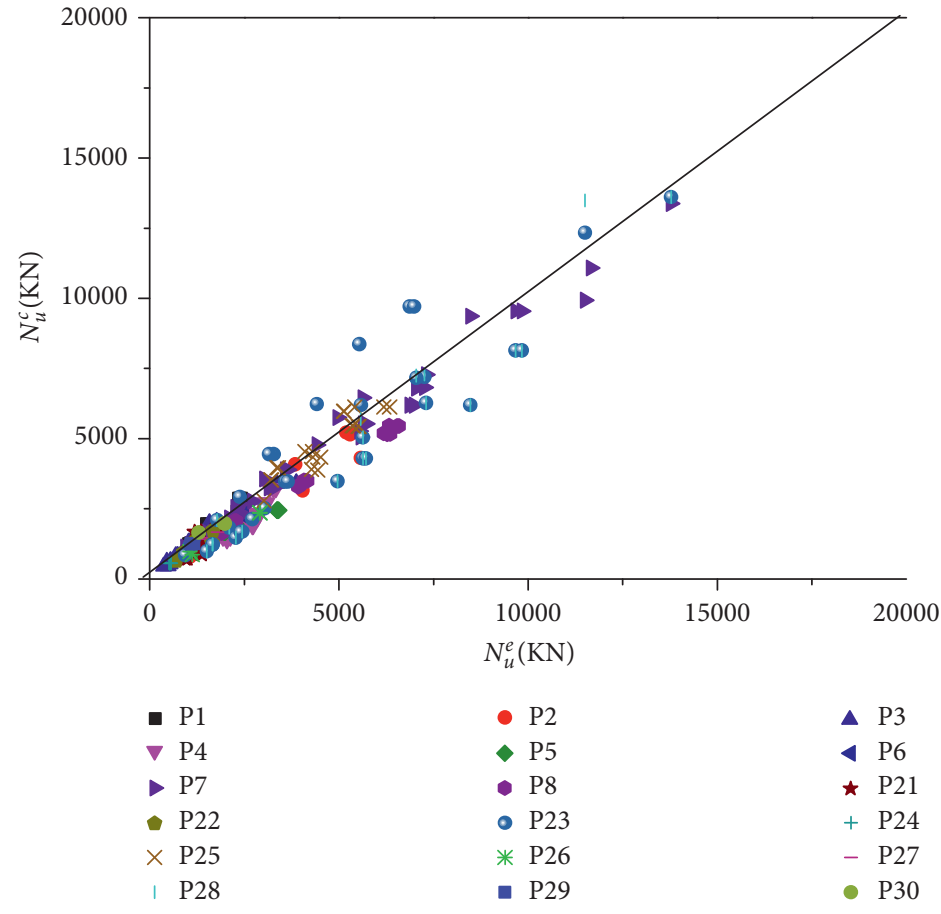

(b)

FIGURE 13: The comparison of calculated result and experiment result of axial compressive bearing capacity.

4.2. Validation of the Proposed Empirical Formulation. In order to verify the correctness of the proposed empirical formulation, the calculated results from formula (2) shown above were compared with test data of fifteen specimens, as can be seen in Figure 13(a). It was found that the mean value, the standard deviation, and the variation coefficient of the CCFST stub columns with the red mud $N_{u}^{c} / N_{u}^{e}$ were 0.989 , 0.024 , and 0.024 , respectively. The result indicates that, in general, the theoretical values of the axial compressive bearing capacity of stub columns agree well with the experimental data.

Due to the limited experimental data of 15 CCFST stub columns with the red mud, the additional experimental data of a total of 325 CCFST stub columns specimens $(r=0 \%)$ from references $[1-8,21-29]$ were introduced in order to further validate the proposed formulation and were compared with the calculated value from formula (2), as can be seen in Figure 13(b). It was found that the mean value, the standard deviation, and the variation coefficient of CCFST stub columns $N_{u}^{c} / N_{u}^{e}$ were $0.938,0.141$, and 0.150 , respectively. In the same way, the theoretical value of the axial compressive bearing capacity of the stub column agrees well with the experimental data as well.

Therefore, formula (2) is applicable to the calculation of axial compressive bearing capacity for the CCFST stub columns with the red mud (as $r=0 \%$ for the CCFST stub columns). Formula calculation value is generally safe and suitable for engineering application.

\section{Conclusions}

Based on the results of this study, the following conclusions can be drawn:

(1) with the increase of the quality substitution rate of the red mud ( $r=0 \% \sim 20 \%)$ in the CCFST stub column with the red mud, the ultimate load increases first and then decreases; on the contrary, the ultimate displacement decreases first then increases; the ultimate load is maximum, as $r=5 \%$, while the ultimate displacement is minimum; as $r=20 \%$, the ultimate load and the ultimate displacement are both nearly the same, respectively, as $r=0 \%$.

(2) As the longitudinal strain of the steel tube is about $1600 \mu \varepsilon$, the specimen reaches the proportional limitation; as the longitudinal strain of steel tube is about $4400 \sim 5000 \mu \varepsilon$, the specimen reaches the yield limitation. When it exceeds yield limitation, as $\xi_{s}=\xi_{0}$, the curve is basically horizontal; as $\xi_{s}>\xi_{0}$, it becomes a slowly rising curve; as $\xi_{s}<\xi_{0}$, it is a gradually falling curve, $\xi_{0}=1.1$.

(3) Empirical formulation of axial compressive bearing capacity of the CCFST stub columns with the red mud is proposed with clear expression, and it is suitable for engineering application.

(4) The experimental data of total 340 specimens, including 15 specimens shown in this paper, were 
compared with calculated results from formula (2). The calculated results agree well with the experimental data, which approve the correctness of the empirical formulation.

\section{Data Availability}

The literature data used to support the findings of this study have been deposited in the CNKI and Duxiu Academic Search repositories (ISBN7-03-012871-0; ISBN 978-7-11406393-0; ISBN7-5611-1071-5; 10.14006/j.jzjgxb.2002.02.006; 10.14006/j.jzjgxb.1999.01.00210.15951/j.tmgcxb.2004.09.001; 10.14006/j.jzjgxb.2017.S1.034; doi:10.1016/j.jcsr.2003.10.001; ISSN 0733-9445/00/0011-1295-1303; ISSN:1708-5284; 10. 1061/(ASCE)ST.1943-541X.0002474; doi.org/10.1016/j.jcsr. 2003.10.001; doi.org/10.1061/(ASCE)0733-9445(2004)130: 2(180); doi.org/10.1016/j.tws.2007.10.001; doi.org/10.1016/j. tws.2016.04.004). The test data used to support the findings of this study are included within the article. Previously reported literature data were used to support this study and are available at (ISBN7-03-012871-0; ISBN978-7-11406393-0; ISBN7-5611-1071-5; 10.14006/j.jzjgxb.2002.02.006; 10.14006/j.jzjgxb.1999.01.00210.15951/j.tmgcxb.2004.09.001; 10.14006/j.jzjgxb.2017.S1.034; doi:10.1016/j.jcsr.2003.10.001; ISSN0733-9445/00/0011-1295-1303;ISSN:1708-5284;10. 1061/(ASCEST.1943-541X.0002474; doi.org/10.1016/j.jcsr. 2003.10.001; doi.org/10.1061/(ASCE)0733-9445(2004)130: 2(180);doi.org/10.1016/j.tws.2007.10.001;doi.org/10.1016/ j.tws.2016.04.004). These prior studies (and datasets) are cited at relevant places within the text as references [1 8] and [21 30].

\section{Conflicts of Interest}

The authors declare that they have no conflicts of interest.

\section{Acknowledgments}

This work was financially supported by the National Natural Science Foundation of China (51574015), Liaoning Province PHD Startup Fund (20170520139), Liaoning Province "Xingliao Talent Program" Project (XLYC1906010), and Liaoning Provincial Communications Technical College 2019 Technology Applied Research Funding Project (LNCCjyky201918).

\section{References}

[1] L. H. Han, Concrete Filled Steel Tubular structures, Science Press, Beijing, China, 2nd edition, 2007.

[2] S. H. Cai, Modern Steel Tube Confined Concrete structures, China Communications Press, Beijing, China, 2nd edition, 2007.

[3] L. H. Han and S. T. Zhong, Concrete Filled Steel Tube Mechanics, Dalian University of Technology Press, Dalian, China, 2nd edition, 1996.

[4] Z. Yu, F. Ding, and L. Song, "Researches on behavior of highperformance concrete filied tubular steel short columns," Journal of Building Structures, vol. 23, no. 2, pp. 41-47, 2002.

[5] K. Tan, X. Pu, and S. Cai, "Study on the mechanical properties of steel extra-high strength concrete encased in steel tubes," Journal of Building Structures, vol. 20, no. 1, pp. 10-15, 1999.
[6] S. Zhang and Y. Wang, "Failure mode of short colums of highstrength concrete-filled steel tubes," China Civil Engineering Journal, vol. 37, no. 9, pp. 1-10, 2004.

[7] K. Sakino, H. Nakahara, and S. Morino, "Behavior of centrally loaded concrete-filled steel-tube short columns," Journal of Structural Engineering, vol. 130, no. 2, pp. 180-188, 2004.

[8] P. Nishiyama, Y. Wang, C. Liu et al., "Experimental study on size effect of circular concrete-filled steel tubular columns subjected to axial compression," Journal of Building Structures, vol. 38, no. S1, pp. 249-257, 2017.

[9] J. Xiao, Q. Zhang, J. Yu et al., "A novel development of concrete structures: Composite concrete structures," Journal of Tongji University (Natural Science), vol. 46, no. 2, pp. 147-155, 2018.

[10] J. Xiao, Z. Lin, and J. Zhu, "Effects of recycled aggregates' gradation on compressive strength of concrete," Journal of Sichuan University (Engineering Science Edition), vol. 46, no. 4, pp. 154-160, 2014.

[11] S. Omary, E. Ghorbel, and W. George, "Relationships between recycled concrete aggregates characteristics and recycled aggregates concretes properties," Construction and Building Materials, vol. 108, pp. 163-174, 2016.

[12] M. Zhou, S. Tian, T. Guo et al., "Experimental research on the concrete using spontaneous combustion gangue as full active material," Bulletin of the Chinese Ceramic Society, vol. 30, no. 5, pp. 1221-1226, 2011.

[13] L. Yan-hua, Li Liang, and Q.-xin Ren, "Mechanical properties of rubber concrete-filled square steel tubular stub columns subjected to axial loading," Journal of Northeastern University (Natural Science), vol. 32, no. 8, pp. 1198-1209, 2011.

[14] J. Chen, Y. Wang, C. W. Roeder, and J. Ma, "Behavior of normal-strength recycled aggregate concrete filled steel tubes under combined loading," Engineering Structures, vol. 130, pp. 23-40, 2017.

[15] L. Ma and Z. Shan-tong, "Strength and lateral deformation coefficient of gangue concrete restrained by steel tube," Journal of Harbin University of C. E.\&Architecture, vol. 35, no. 3, pp. 20-23, 2002.

[16] A. Silva, Y. Jiang, J. M. Castro, N. Silvestre, and R. Monteiro, "Monotonic and cyclic flexural behaviour of square/rectangular rubberized concrete-filled steel tubes," Journal of Constructional Steel Research, vol. 139, pp. 385-396, 2017.

[17] W. Liu, J. Yang, and B. Xiao, "Review on treatment and utilization of bauxite residues in China," International Journal of Mineral Processing, vol. 93, no. 3-4, pp. 220-231, 2009.

[18] X. Liu, N. Zhang, and H. Sun, "Structural investigation relating to the cementitious activity of bauxite residue-Red mud," Cement and Concrete Research, vol. 41, no. 8, pp. 847-853, 2011.

[19] R-X. Liu and C.-S. Poon, "Utilization of red mud derived from bauxite in self-compacting concrete," Journal of Cleaner Production, vol. 112, pp. 384-391, 2016.

[20] B. Wu, Z. Tan, Y. Zhang, Z. Zhao, C. Liu, and Q Wang, "Experiment research on the bond-slip behavior of red mud concrete filled square steel tubes," Journal of Henan Polytechnic University (Natural Science), vol. 38, no. 4, pp. 148-153, 2019.

[21] G. Giakoumelis and D. Lam, "Axial capacity of circular concrete-filled tube columns," Journal of Constructional Steel research, vol. 60, pp. 1049-1068, 2004.

[22] D. Lam and C. Roach, "Axial capacity of concrete filled stainless steel circular columns," Welding in the World, vol. 50, pp. 448-454, 2007.

[23] M. D. O'Shea and R. Q. Bridge, "Design of circular thin-walled concrete filled steel tubes," Journal of Structural Engineering, vol. 126, no. 11, pp. 1295-1303, 2000. 
[24] M. Mimoune, F. Z. Mimoune, and M. Ait Youcef, "Axial capacity of circular concrete-filled steel tube columns," World Journal of Engineering, vol. 8, no. 3, pp. 237-244, 2011.

[25] J. Wei, X. Luo, Z. Lai, and A. H. Varma, "Experimental behavior and design of high-strength circular concrete-filled steel tube short columns," Journal of Structural Engineering, vol. 146, no. 1, pp. 1-16, Article ID 04019184, 2020.

[26] N. J. Gardner and R. Jacobson, "Structural behavior of concrete filled steel tubes," ACI Journal, vol. 64, no. 7, pp. 404-413, 1967.

[27] G. Giakoumelis and D. Lam, "Axial capacity of circular concretefilled tube columns," Journal of Constructional Steel Research, vol. 60, no. 7, pp. 1049-1068, 2004.

[28] Q. Yu, Z. Tao, and Y.-X. Wu, "Experimental behaviour of high performance concrete-filled steel tubular columns," Thin Walled Structres, vol. 46, no. 4, pp. 362-370, 2008.

[29] T. Ekmekyapar and B. J. M. Al-Eliwi, "Experimental behaviour of circular concrete filled steel tube columns and design specifications," Thin Walled Structures, vol. 105, no. 8, pp. 220-330, 2016. 